
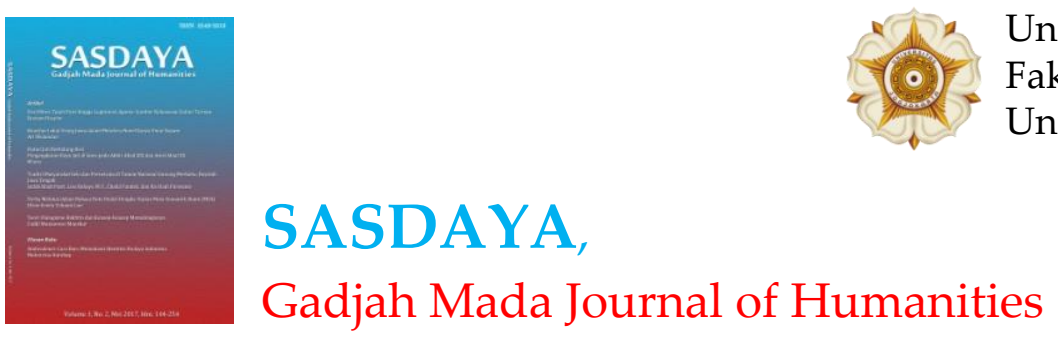

ISSN: 2548-3218 (print); ISSN : 2549-3884 (online); website: https://jurnal.ugm.ac.id/sasdayajournal

Kita and Dunia Kontemporer (Atau Mengapa Sejarawan Harus Menyesuaikan Cara Kerjanya Dengan Tuntutan Perkembangan Teknologi Informasi Digital)

We and Contemporary World (or Why Historians must be Their Adjust Method of Work with Developments of Digital Technology Information)

Penulis/Author(s): Agus Suwignyo

Sumber/Source :SASDAYA, Gadjah Mada Journal of Humanities, Vol. 2, No. 2 (May 2018), pp. 393-404

Penerbit : Unit Penelitian dan Publikasi Fakultas Ilmu Budaya Universitas Gadjah Mada, Indonesia

Copyright (c) 2018 SASDAYA: Gadjah Mada Journal of Humanities

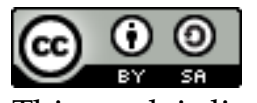

This work is licensed under a Creative Commons Attribution-ShareAlike 4.0 International License. 


\title{
KITA DAN DUNIA KONTEMPORER (ATAU MENGAPA SEJARAWAN HARUS MENYESUAIKAN CARA KERJANYA DENGAN TUNTUTAN PERKEMBANGAN TEKNOLOGI INFORMASI DIGITAL)
}

\author{
Agus Suwignyo ${ }^{1}$
}

\begin{abstract}
During this time has often heard the review that in the last 15 years, the interest of people in Indonesia to the history and study of history has grown very rapidly. This is evident in the number and variety of historical book titles sold in bookstores, and on often posting various historical events on social media. Nevertheless, the history as taught in the school classrooms as well as in the lecture does not seem to go anywhere. New writing and teaching efforts of history lessons/courses are still focused on models and the results of formal studies that are state-centric in nature. In particular, historical writing and teaching efforts face the challenge of emerging changes from the global connectivity of information technology as a historical fact of the contemporary world that is becoming. The contemporary world presents a new challenge in the study and teaching of history through the development of digital communications technology. This paper reviews historical positions and historians in the rapid dynamics of the development of digital communications technology. Why and how historians should develop a proper perspective in placing their studies in the current era of digital technology? Papers process data using digital technology and contrast it with the model and approach of historical study in Indonesia so far.
\end{abstract}

Key word: era digital, penelitian sejarah, historiografi baru

\section{PENDAHULUAN}

Keterhubungan global dalam kehidupan sehari-hari adalah fakta sejarah yang sedang menjadi saat ini. Perkembangan teknologi komunikasi kuncinya. Artikel ini mencoba mengulas posisi sejarawan dan kajian sejarah dalam dinamika cepat perkembangan teknologi komunikasi digital. Mengapa dan bagaimana sejarawan harus mengembangkan cara pandang dan cara kerja yang tepat dalam menempatkan peristiwa sejarah dalam kajian-kajiannya di era teknologi digital saat ini? Apa yang disebut "era teknologi informasi" atau "era digital" menunjuk pada periode

\footnotetext{
${ }^{1}$ Staf Pengajar Jurusan Sejarah, Fakultas Ilmu Budaya Universitas Gadjah Mada,
} Yogyakarta. Penulis bisa dihubungi melalui email: suwignyo_agus@ugm.ac.id 
meluasnya pemanfaatan internet sebagai saluran interaksi dan dampak-dampak yang ditimbulkannya baik secara ekonomi, politik maupun sosial-budaya.

Tigapuluh tahunan yang lalu, banyak orang meragukan dan tidak percaya ulasan para pemikir tentang pergerakan pola interaksi masyarakat dunia yang semakin tak berstruktur dan tak berbatas oleh ruang fisik. Buku Alvin Toffler, The Third Wave (1980), dirayakan besar-besaran oleh kalangan liberal progresif, tetapi dikritik habis oleh mereka yang tertumpu pada kemapanan dan status quo, baik dari aliran kanan maupun kiri pada masanya. Toffler menyebut era informasi (information age) sebagai gelombang ketiga revolusi peradaban manusia menyusul era industri dan era pertanian. Kajian sosiolog Manuel Castell (2000) telah secara rinci dan kritis menguraikan titik-mula, proses dan trajektori perubahan-perubahan masyarakat pada era informasi. Castell menyatakan bahwa era informasi akan dibarengi dengan berkembangnya pasar kerja berbasis pengetahuan (knowledge-based labor market) yang mengubah semua pola dan struktur hubungan majikan-buruh yang berkembang dari arus Gelombang Kedua. Sementara itu sosiolog Jeremy Rifkin (1995) mengatakan bahwa pola relasi pada masyarakat informasi menciptakan karakter pasar kerja yang lentur dan cepat berubah (protean) menyangkut kriteria kualifikasi sumber daya manusia. Khususnya pada negara-negara maju, mobilitas tenaga ahli dan madya telah lama menjadi ciri pasar ekonomi terintegrasi. Pada negara-negara berkembang seperti Indonesia, pola serupa baru mulai berlangsung kira-kira sepuluh tahun terakhir lewat kesepakatan pasar bebas kawasan (ASEAN dan ASEAN Plus). Keterhubungan global secara perlahan tapi pasti telah mengubah struktur ekonomi dan politik dalam relasi antarbangsa. Apa yang diproyeksikan banyak filsuf sosial sejak dekade 1970an, kini mewujud di dalam kehidupan sehari-hari kita. Keterhubungan global dan semua konsekuensinya adalah sejarah kontemporer yang secara fundamental menciptakan goncangan peradaban.

Apa yang telah dan sedang berlangsung menyangkut keterhubungan global dengan kemajuan teknologi informasi sebagai kuncinya itu, adalah fakta sejarah dunia. Di sini apa yang disebut "sejarah dunia" bukan sesuatu yang jauh dari kehidupan sehari-hari kita, bukan suatu peristiwa yang pola kejadiannya berskala besar, tetapi sesuatu yang melekat menyatu dalam bentuk dan roh aktivitias dari detik ke detik. Sejarah dunia kontemporer adalah seliweran informasi yang setiap detik kita konsumsi atau distribusikan nyaris lapisan penyaring. Fakta ini telah menghadikan goncangan bagi banyak bidang kehidupan dan cara-cara kajian atasnya. Pertanyaannya, sejauh mana keterhubungan global sebagai sejarah dunia yang sedang menjadi itu, telah mengubah cara kerja sejarawan dan pendekatan atas bidang kajian sejarah? Dikatakan dalam cara lain, sejauh mana sejarawan telah merespons goncangan keterhubungan global itu di dalam kerja akademiknya?

Jika selama sekitar 15 tahun terakhir di Indonesia, yaitu pada periode politik yang disebut "Reformasi", ada gejala peningkatan peminat sejarah dan jumlah pembelajar sejarah, apakah peningkatan peminat sejarah itu juga berimplikasi pada pendekatan kajian dan pembelajaran sejarah dalam respons atas goncangan keterhubungan global akibat kemajuan teknologi informasi? Sebagaimana ditulis Anthony Reid, saat ini kajian-kajian dalam bidang sejarah secara khusus dan dalam bidang humaniora secara umum dituntut untuk merengkuh isu-isu yang muncul dari dinamika global. Kajian-kajian Humaniora dan sejarah khususnya dituntut keluar 
dari-meski tanpa meninggalkan-paradigma struktural yang konvensional untuk melihat kembali perisitiwa sejarah dalam bingkai keterhubungan global kekinian yang sangat dinamis. "Sebagai akademisi dan profesional kita harus bergerak secara pasti dari yang national kepada yang global, mengubah jalan yang mendangkal dalam merayakan identitas dan warisan nasional menjadi upaya menjelaskan jalinan dunia yang semakin kompleks," tulisnya (Reid 2016: 11).

Pada kajian sejumlah studi disebutkan bahwa era teknologi informasi telah bermula pada awal dekade 1970an di Amerika Serikat dengan penemuan piranti keras komputer dan perangkat lunak sistem internet. Embrio teknologi komputer ini adalah kerja laboratorium oleh ahli fisikawan Inggris yang menemukan alat dekodifikasi sandi untuk kebutuhan Perang Dunia II. Dalam waktu sekitar seperempat abad selanjutnya, teknologi komputer berbasis internet telah mengalami perkembangan sangat pesat.

Meskipun demikian, pemanfaatan teknologi komputer berbasis internet baru benar-benar menjadi trend global dunia setelah berakhirnya Perang Dingin di penghujung abad keduapuluh. Pada periode pasca berakhirnya Perang Dingin itu pula kita menyaksikan dua penanda penting lainnya atas peristiwa-peristiwa dunia. Pertama adalah perubahan tata dunia yang sangat drastis dalam aneka peristiwa yang secara ideologis menjadi apa yang oleh Samuel Huntington (1996) disebut "benturan peradaban". Kedua, meningkatnya perhatian dunia pada isu-isu lingkungan dan perubahan iklim (Anthony Giddens, 2009). Karena itu jika istilah "kontemporer" kita batasi sebagai "rata-rata usia ingatan manusia" - yang adalah sekitar 20 tahun - maka dunia kontemporer saat ini merentang dari kira-kira dekade 1990 hingga kini (2017).

Dalam periode kontemporer ini dunia telah ditandai oleh berbagai peristiwa besar yang dapat dikategorikan ke dalam empat kelompok peristiwa penanda. Pertama adalah berakhirnya Perang Dingin itu sendiri. Runtuhnya blok Komunis memunculkan kembali banyak entitas negara-bangsa dan mengubah struktur politik dunia. Kedua, salah satu dampak perubahan struktur politik lahirnya konflik yang berakar pada apa yang oleh Samuel Huntington disebut "benturan peradaban". Konflik ini bersifat transnasional karena cenderung tidak mengenal batas negara. Pemicu konflik dapat berupa ketidakseimbangan ekonomi atau lainnya, tetapi bungkus semua konflik adalah ideologi, khususnya agama. Ketiga, sebagaimana telah diuraikan, dunia kontemporer juga ditandai oleh meluasnya perhatian terhadap persoalan-persoalan perubahan iklim dan permasalahan lingkungan. Akhirnya, penanda besar keempat dari dunia kontemporer adalah perkembangan internet dan teknologi komunikasi digital.

Artikel ini akan berfokus secara khusus pada penanda keempat tersebut. Bagaimana sejarawan menyikapi perkembangan pesat dunia sehari-hari akibat kemajuan teknologi informasi tersebut di dalam pendekatan kajian dan pengajaran sejarah? Artikel pertama-tama akan mengulas aspek perkembangan teknologi informasi digital secara global dan dampak sosial dan lainnya yang ditimbulkannya. Kemudian akan diulas profil masyarakat digital Indonesia sebagaimana dapat dipotret pada kelas menengahnya. Terakhir akan didiskusikan posisi dan peluang terkait sejarawan pada perkembangan pesat dunia kontemporer.

\section{REVOLUSI ALAT KOMUNIKASI INTERAKTIF}


Dunia telekomunikasi telah mengalami revolusi sangat drastis baik terkait tekonologi alat maupun salurannya. Pada masanya kita mengenal pesawat telepon sebagai alat komunikasi yang maju. Alat itu menghubungkan komunikasi lisan manusia meskipun mereka terpisah oleh rentang jarak fisik. Sejak paten pertama dibukukan pada sistem paten Amerika Serikat oleh Alexander Graham Bell tahun 1876 (https://en.wikipedia.org/wiki/Alexander Graham Bell), telah terjadi perkembangan pesat alat telepon hingga kita mengenal saluran telepon di dalam rumah dan telepon umum dengan sistem koneksi pulsa koin dan kartu. Hingga tahun 1990an, alat telepon umum masih berlaku dan digunakan hampir di seluruh dunia sebagai model komunikasi interaksi lisan yang paling efektif. Gambar 1a dan 1 b menunjukkan model alat telepon umum yang berlaku di Inggris tahun 1992. Alat-alat serupa dapat kita jumpai di berbagai kota besar di dunia ketika itu.

\section{Foto 1a dan 1b: Model alat komunikasi lisan-interaktif global hingga 1990an}
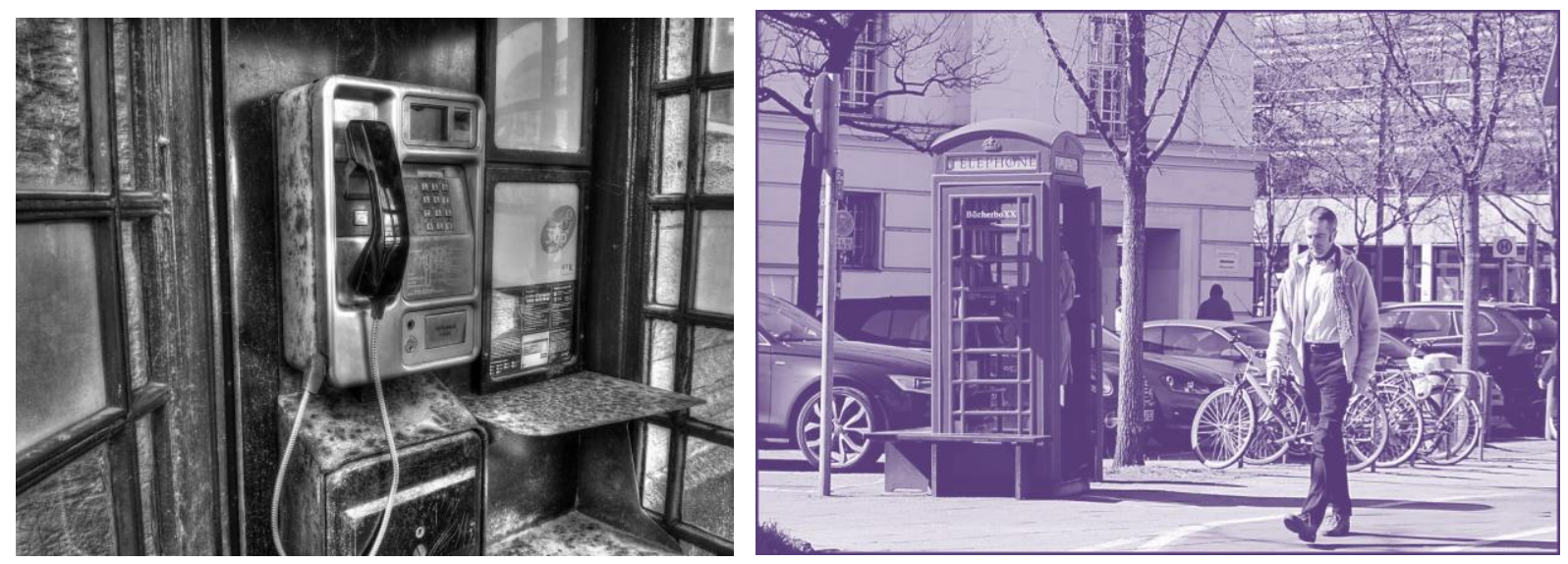

(Sumber: https://hiveminer.com/Tags/england,telefonzelle)

Model telepon genggam atau telepon seluler mulai merambah secara global pada awal abad ke-21 atau sekitar tahun 2000. Alat telepon seluler (di Indonesia dikenal sebagai HP, handphone) berbeda sama sekali dengan alat telepon konvensional. Alat telepon seluler memungkinkan mobilitas pemakainya ke manapun dan tidak terikat secara fisik pada satu tempat saja. Teknologi seluler juga memungkinkan komunikasi individual secara langsung baik melalui suara maupun teks. Perkembangan selanjutnya dari teknologi ini, melalui apa yang disebut telepon pintar (smartphone), menciptakan semua kemungkinan digital baik melalui suara, teks, gambar mati maupun gambar hidup (video) secara langsung (live) maupun tayang ulang (relay) (Foto 2a dan 2b). 
Pergantian dari saluran telepon kabel ke telepon nirkabel, dan pergantian dari teknologi seluler analog ke teknologi telepon pintar, telah mengubah sejumlah karakter manusia sebagai individu dan sebagai komunitas. Misalnya menyangkut batasan tentang privasi. Sebelum dikenal teknologi komunikasi digital dan berjejaring, kebanyakan orang merasa tidak nyaman jika hal-hal yang terkait aktivitas personal hariannya diketahui orang banyak. Namun sekarang dengan sangat mudah kita menemukan gejala sosial masyarakat ketika seseorang menulis post di dinding media sosial tentang kondisi perutnya yang sakit. Orang melakukan foto diri (selfie) dan mengunggah foto tersebut ke ruang publik virtual. Batas antara privat dan publik telah berubah secara drastis.

\section{Foto 2a dan 2b: Model alat komunikasi era informasi (telepon seluler analog dan telepon pintar)}
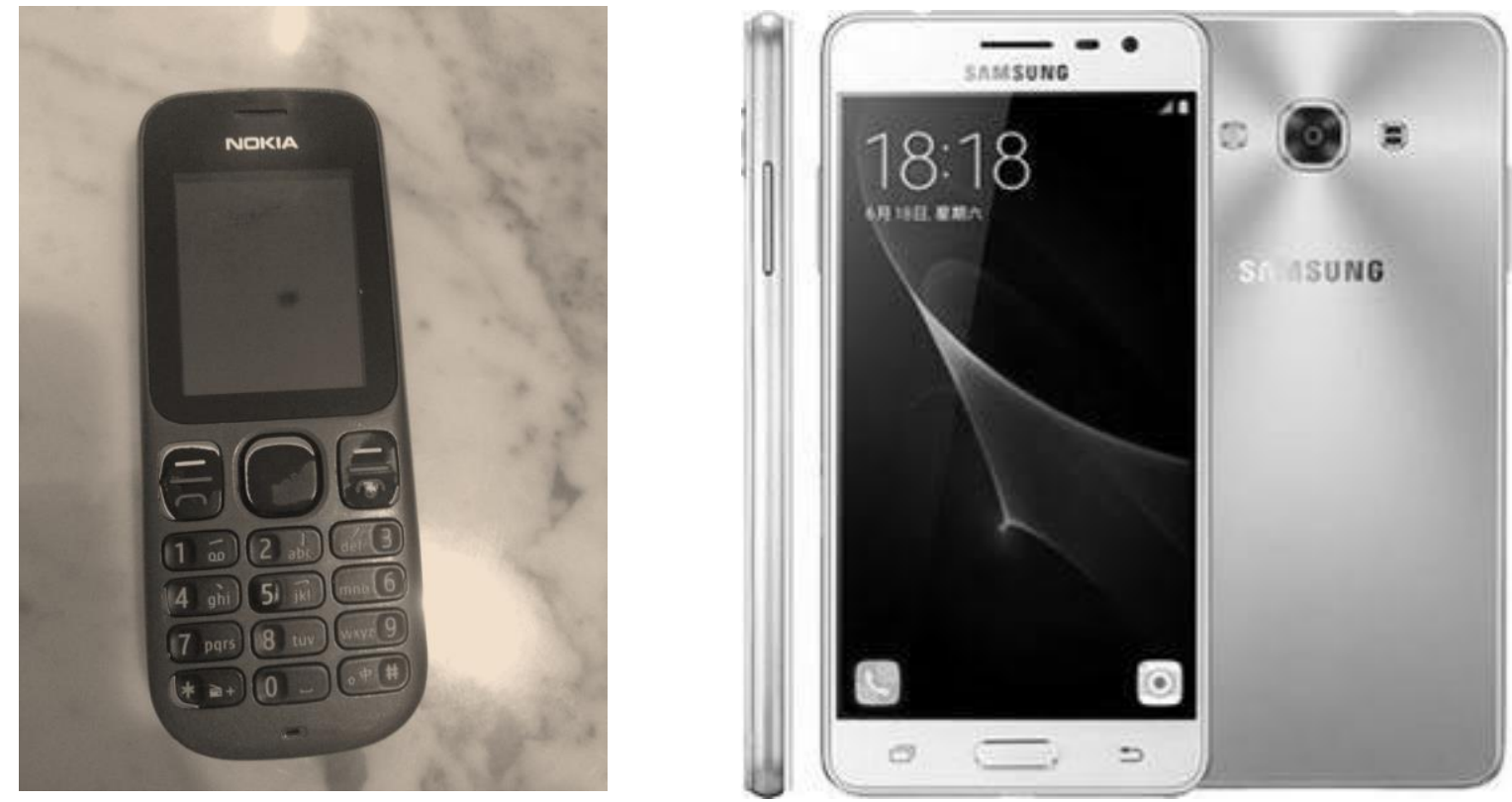

Foto analog oleh penulis

Sumber foto smartphone: Https://Www.Bukalapak.Com/P/Handphone/Hp-Smartphone/5oe93t-JualSamsung-Galaxy-J3-Pro-2017-Free-Ongkir-Dual-Sim-16gb-Ram-2gb-Bnib-New-Original?Blca=SeshoAwalp\&Gclid=Eaiaiqobchmiqpgig-V91givvafoch0bvw9keaqyasabegjaupd_Bwe

Gejala baru perilaku individu di dalam masyarakat menunjukkan sifat paradoksal. Paradoks itu mungkin dapat dirumuskan sebagai fenomena "dekat menjauh, jauh mendekat". Ada kecenderungan individu-individu yang berada dalam satu kumpulan lokalitas fisik, tidak betul-betul berinteraksi intens di antara mereka sekalipun mereka memiliki ikatan sosial yang kuat, misalnya keluarga maupun teman-teman dekat. Kita tidak jarang menjumpai satu keluarga pergi ke sebuah 
restoran. Sambil menunggu pesanan makanan datang dan selama proses makan, tidak terlihat saling komunikasi lisan langsung terjadi di antara mereka. Masing-masing sibuk dengan alat gawainya. Demikian pula di berbagai kesempatan lain seperti ruang kuliah, gejala perilaku serupa itu semakin umum terjadi. Hal ini merupakan gejala baru perilaku masyarakat yang dalam konteks Indonesia berkembang seiring dengan meluasnya pemakaian teknologi komunikasi digital berbasis jaringan. Ada gejala orang semakin menarik diri dari komunikasi langsung fisik dan menjadi semakin berfokus secara fisik pada dirinya sendiri. Mungkin sebutan "alienasi-diri" tepat untuk menunjuk kecenderungan "pengucilan-diri" dari lingkungan fisik langsung. Tetapi pada saat yang sama ketika individu-individu itu mengasingkan diri di tengah jalinan sosial lingkungan fisik di mana mereka berada, mereka menjadikan dirinya bagian dari "masyarakat virtual", yaitu kumpulan orang yang tidak harus salingmengenal dan tidak harus berada di satu kesatuan lokalitas fisik, tetapi menjalin jejaring komunikasi dan interaksi secara intens melalui media dan teknologi komunikasi digital. Gejala-gejala baru perilaku dapat ditelusuri lebih jauh.

\section{Foto 3a dan 3b: Telephone booth di Kota London, menjadikan yang lama baru}

Sumber: koleksi foto penulis, Agustus 2017
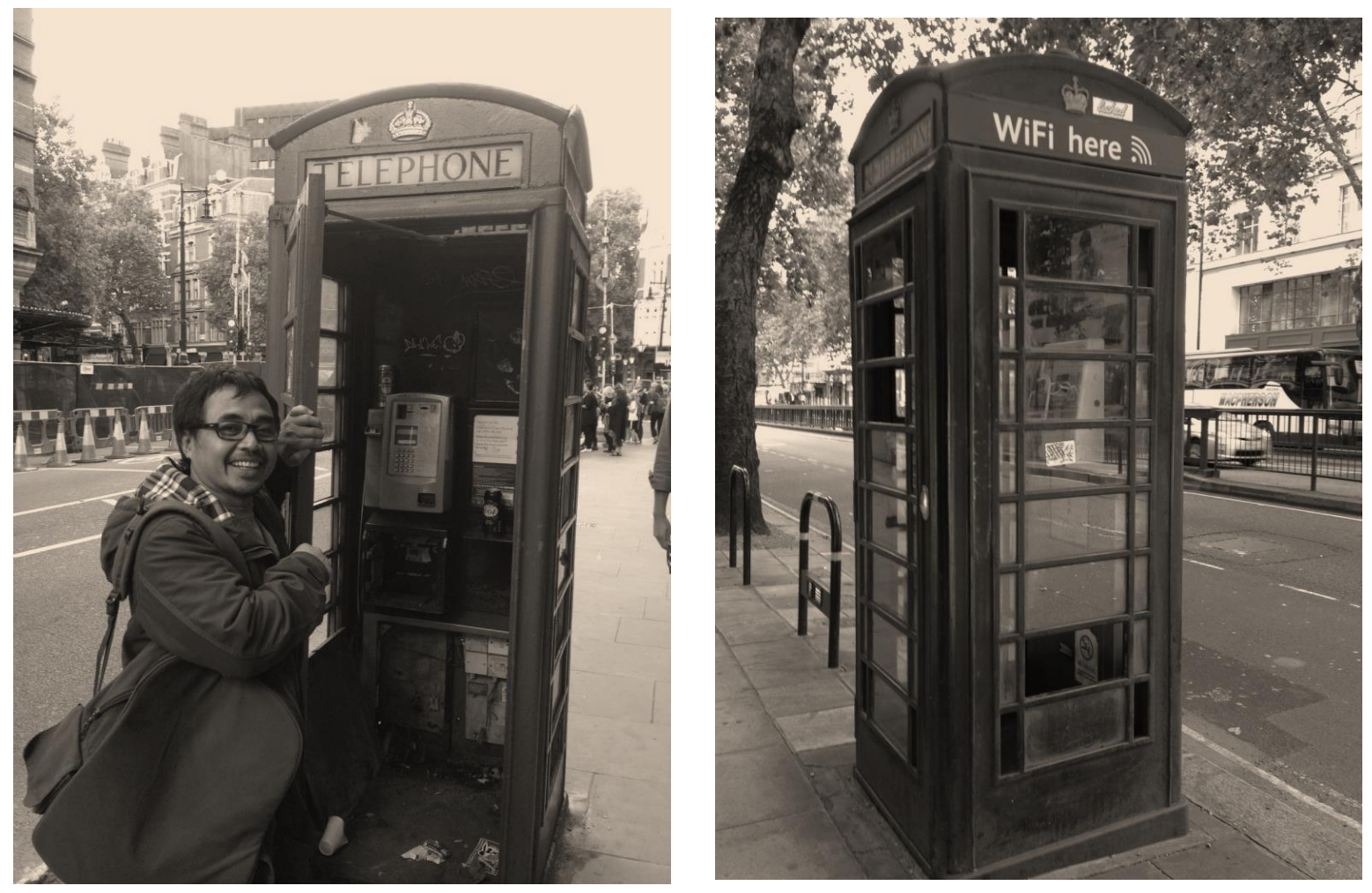

Meskipun kemajuan teknologi komunikasi digital telah mengubah banyak hal sebagaimana telah disinggug, ada gejala juga bahwa masa lalu yang secara praktis telah lampau dan tidak berlaku lagi, tetap dipertahankan dalam simbol-simbol ingatan bersama. Mungkin kasus telephone booth di London, Inggris bisa diambil sebagai 
contoh yang menarik. Sebagaimana tampak pada gambar pada Foto 3a dan 3b, telepon umum yang ditempatkan di dalam strukutur kotak setinggi orang itu saat ini sudah tidak berfungsi/difungsikan lagi. Telepon tersebut berkabel dan saat ini model dan aplikasinya telah digeser/tergeser oleh teknologi komunikasi digital berjejaring. Meskipun, pemerintah Kota London memutuskan tetap mempertahankan booth telepon di tempatnya dan seperti apa adanya. Fungsi booth sebagai rumah telepon berkabel yang telah mati, digantikan oleh jaringan nirkabel berupa layanan Wi-Fi (Wireless Fidelity) area. Titik pada bekas tempat booth telepon kabel terletak dan sekitarnya, sekarang merupakan wilayah bebas akses internet dan-tentu saja - askes pada komunikasi berjejaring. Kebijakan pemerintah Kota London ini menunjukkan betapapun kenangan dan ingatan bersama tentang teknologi telepon di masa lalu dan semua dampak sosiologisnya merupakan suatu warisan yang perlu dipertahankan. Transformasi telephone booth di Kota London menjadi area Wi-Fi secara simbolis merepresentasikan upaya mempertahankan sekaligus memodernisasi ingatan kolektif tentang keberadaan alat komunikasi itu, tetapi sekaligus mencerminkan kesiapan dan ajakan pemerintah untuk menyesuaikan diri dengan kemajuan-kemajuan jaman.

\section{PROFIL MASYARAKAT DIGITAL INDONESIA}

Di Indonesia, kemajuan global teknologi informasi digital nyata terasa. Saat ini, Indonesia adalah salah satu "raksasa teknologi digital", menduduki nomor 4 dunia setelah Cina, India dan Amerika Serikat. Tahun 2015, di Indonesia ada 86,6 juta pengguna internet. Angka ini naik sekitar 33\% dari profil tahun 2014. Dari jumlah itu, $34 \%$ di antaranya menggunakan saluran internet broadband. Penetrasi internet (persebaran penggunaan internet) Indonesia tahun 2014 adalah 17\%. Prosentase tersebut masih lebih rendah dibandingkan India (19\%), Filipina (39\%), Malaysia (40\%), Vietnam (43\%) dan Singapura (81\%). Jumlah pengguna cellphone atau telepon seluler di Indonesia tahun 2014 ada 281,9 juta orang. Angka tersebut jika dihitung proporsional dengan jumlah penduduk menghasilkan hitungan 1.13 unit cellphone setiap jiwa penduduk. Sebaran usia pengguna adalah rentang $20-39$ tahun $(69,3 \%)$ dan 40-59 tahun (28.3\%). Di luar 2 kategori rentang usia ini angka prosentase penggunaan cellphone adalah kecil. Artinya cohort terbesar pengguna cellphone di Indonesia adalah usia produktif. Angka-angka ini menyimpan potensi ekonomi langsung. Pertama, dari jumlah 92 startsup di Asia Tenggara tahun 2014, 24 di antaranya berasal dari Indonesia. Kedua, angka belanja online (dalam jaringan) sejumlah toko retail dan aplikasi jasa layanan sangat besar. Misalnya, belanja online MatahariMall mencapai Rp 6.51 triliun sedangkan total transaksi Gojek mencapai Rp 2.8 triliun dan Tokopedia $\mathrm{Rp} \quad 1.4$ triliun (data dari https://www.goodnewsfromindonesia.id/2016/01/21/data-terbaru-ternyata-jumlahponsel-di-indonesia-melebihi-jumlah-populasi; http://www.tempo.co/read/kolom/ 2015/10/02/2310/indonesia-raksasa-teknologi-digital-asia; dan https://www.kominfo.go.id/content/detail/6095/indonesia-raksasa-teknologi-digitalasia/0/sorotan_media).

Dalam kaitan dengan aspek digital itu, penting melihat struktur sosial ekonomi penduduk Indonesia sebagai pelaku di dalam masyarakat digital. Bank Dunia 
menunjukkan struktur sosial ekonomi penduduk Indonesia sebagian besar atas kelas menengah. Data Bank Dunia diperkuat oleh hasil survei Harian Kompas, yang menunjukkan bahwa komposisi kelas menengah Indonesia merupakan porsi terbesar penduduk saat ini. Menurut kriteria Bank Dunia, kategori kelas atas adalah mereka yang berpenghasilan lenih dari 20 dolar Amerika per hari. Kelas menengah atas berpenghasilan antara 11 hingga 20 dolar Amerika tiap hari. Kelas menengah, 5-10 dolar Amerika tiap hari. Kelas menengah bawah, 2-4 dolar per hari dan kelas bawah kurang dari 2 dolar per hari. Data Bank Dunia menunjukkan secara relatif bahwa struktur sosial ekonomi masyarakat Indonesia terdiri atas sebagian besar kelas menengah yaitu 56,5\% dari total 237 juta penduduk tahun 2012. Pertumbuhan jumlah kelas menengah Indonesia adalah 65\% dalam rentang 9 tahun (2003-2012). Sementara itu Survei Harian Kompas menunjukkan komposisi struktur sosial eknomi masyarakat secara lebih rinci. Menurut survei Kompas, penduduk Indonesia tersegmentasi sebaga berikut: $1 \%$ kelas atas, 3,6\% kelas menengah atas, 50,2\% kelas menengah, 39.6\% kelas menengah bawah dan 5,6\% kelas bawah. Indikator penentuan kategori struktur yang dipakai Kompas adalah kriteria Bank Dunia tentang ciri-ciri ekonomi kategori kelas yang telah disebutkan (data dari: http://nasional.kompas.com/read/2012/06/08/03204285/wajah.baru.kelas.menengah.in donesia; $\quad$ http://nasional.kompas.com/read/2012/06/08/13003111/Siapa.Kelas. Menengah.Indonesia)

Dua set data menunjukkan detil angka yang berbeda tetapi intinya sama, yaitu bahwa kelas menengah dan kelas menengah bawah merupakan klaster terbesar penduduk secara social ekonomi. Jika dihitung dengan angka nominal, maka sekitar 118 juta penduduk Indonesia masing-masing menghasilkan antara 5 hingga 10 dolar Amerika per hari. Diambil rata-rata penghasilan adalah 7.5 dolar Amerika per hari, maka 118 juta penduduk Indonesia tersebut menghasilkan kekuatan ekonomi ekuivalen dengan 885 juta dolar Amerika setiap hari. Sementara itu, kelas menengah bawah jumlahnya terbesar kedua setelah kelas menengah, yaitu 39,6\% atau sekitar 94 juta jiwa. Jika masing-masing dari mereka menghasilkan rata-rata 3 dolar Amerika per hari, maka penghasilan kumulatif kelas menengah bawah Indonesia sekitar 282 juta dolar Amerika setiap hari. Jadi, dari 2 kategori kelas ekonomi, yaitu kelas menengah dan kelas menengah bawah yang merupakan 2 klaster terbesar dalam struktur ekonomi penduduk, Indonesia memiliki peredaran uang sekitar 1 milyar 167 juta dolar Amerika per hari. Angka-angka ini tentu memiliki makna yang besar dalam menggerakkan transformai sosial politik dalam lingkup yang luas.

Ciri-ciri kelas menengah Indonesia menurut survei Harian Kompas, tidak jauh dari dunia teknologi digital. Mereka rata-rata memiliki lebih dari 1 smartphone, gampang memperoleh uang tetapi juga royal dalam membelanjakannya. Mereka bekerja selama 8-10 jam per hari, berorientasi high-profile dan menunjukkan perilaku kosmopolitan. Pekerjaan kelas menengah bervariasi antara pengusaha, profesional, pejabat menengah pemerintah dan lain-lain. Paparan ini memberikan gambaran bahwa keterhubungan global dan semua aspek kemajuan teknologi informasi digital telah dan sedang membentuk masyarakat Indonesia menjadi bagian dari komunitas virtual global. Dampak dan konsekuensi terkait hal ini amat luas dan menyentuh semua sisi dan bidang kehidupan kita sehari-hari. Semua bergerak ke dalam dua sisi klasik tantangan dan peluang. 


\section{MANA POSISI KAJIAN SEJARAH DAN SEJARAWAN?}

Di tengah semua gerak dinamis kemajuan dan kekuatan serta konsekuensikonsekuensi yang terus berubah dan mengubah di dalam masyarakat dunia kontemporer itu, di mana posisi kajian sejarah dan para sejarawan? Teknologi telepon seluler berbasis jaringan (internet) menciptakan apa yang disebut virtual reality (realitas virtual, yaitu kenyataan secara tak fisik) yang mengubah paradigma kita tentang fakta. Realitas hari ini dapat tampil tanpa harus mengambil bentuk ruang. Sebuah peristiwa sebagai sebuah realitas virtual berlangsung dalam lesapan waktu yang sangat cepat dan menyamarkan makna periode sebagai satu cakupan waktu. Meskipun tak fisik dan nir-ruang dan nir-waktu, realitas virtual memegang kunci bagi terciptanya realitas konvensional. Sebuah posting pada laman media sosial (realitas virtual), misalnya, dapat berubah menjadi gerakan massa (realitas fisik) tetapi karakter dasar kenyataan tersebut terbentuk dari elemen-elemen yang sama sekali berbeda dari struktur konvensional suatu peristiwa.

Berkembangnya jenis lain realitas berimplikasi banyak pada sifat dan proses terjadinya peristiwa. Peristiswa virtual - misalnya berkembangnya suatu topik pada sirkulasi ketersebaran di dunia maya yang disebut viral-dapat berlangsung sangar cepat dalam hitungan detik. Artinya, selain tidak mengambil ruang fisik, kecepatan terjadinya suatu peristiwa virtual juga mempersempit ruang waktu. Keterlampauan suatu peristiwa tidak terlalu terpaku pada patokan waktu/kronos sebagaimana selama ini telah konvensional. Apa yang disebut "periode" di jaman teknologi digital adalah suatu ruang tipis yang dipagari hanya oleh satuan kronos terkecil dalam sistem waktu manusia bumi, yakni detik. Kemajuan semua program komunikasi yang melekat pada fungsi teknologi telepon pintar, yang dikenal sebagai sosial media, telah mengambil secara massif apa yang disebut "ruang" jarak dan "ruang" waktu dari struktur yang dipahami dan disepakati masyarakat manusia selama ini tentang periistiwa.

Dampak relatif dari semua kemajuan itu, yang dapat bersifat positif maupun negatif, bukanlah perhatian artikel ini. Dan saya tidak dalam posisi untuk mengulas aspek-aspek moral masyarakat yang strukturnya telah dan sedang bertransformasi drastis secara global akibat kemajuan teknologi komunikasi digital. Kepentingan saya di sini adalah mengajukan pertanyaan, sejauh mana semua kemajuan teknologi komunikasi digital dan transformasi global yang sedang berlangsung itu telah menjadi platform dan paradigma kerja sejarawan? Ketika banyak orang percaya kemajuan teknologi komunikasi digital adalah fakta kontemporer global yang tak mungkin dihindari, maka tantangan baru telah menghadapkan sejarawan pada kebutuhan dan keharusan memperbarui cara kerjanya agar lebih compatible (pas sesuai takaran) jaman yang terus berubah. Seperti dikatakan Anthony Reid, "Kita [sejarawan] perlu mengkaji sejarah, pra-sejarah atau sejarah-mendalam pada kaitan dengan bidang sains, agama dan budaya pada skala global" (Reid,2016: 11).

Secara klasik, konstruk negara-bangsa telah menjadi titik-pijak utama kerja para sejarawan. Dari "negara-bangsa", kajian-kajian sejarah telah berkembang ke segala arah untuk mengupas berbagai objek kajian pada tiga klaster besar, yaitu politik, ekonomi dan sosial-budaya. Titik pijak ini melahirkan model kajian sejarah yang institusional dari segi pendekatan dan bangun narasi. Model kajian institusional 
membedah struktur suatu fenomena berdasarkan objek material apa saja, namun skala dan inti kajian terpaku pada sifat difusionis yang melekat pada struktur inheren objek tersebut. Pada era teknologi komunikasi digital, tercerabutnya peristiwa dari dimensi ruang fisik dan ruang waktu yang selama ini dipersepsikan oleh sejarawan secara ketat sebagai kerangka lingkup atasnya, menghadirkan tantangan bagi para sejarawan untuk keluar dari kerangka paradigmatik "negara-bangsa" baik dalam pendekatan maupun orientasi produk kerjanya.

Foto 4a dan 4b: Sumber primer, tipikal objek material dalam kajian sejarah Sumber foto: Koleksi penulis, dengan courtesy Tim Penelitian Madiun 2016-2017
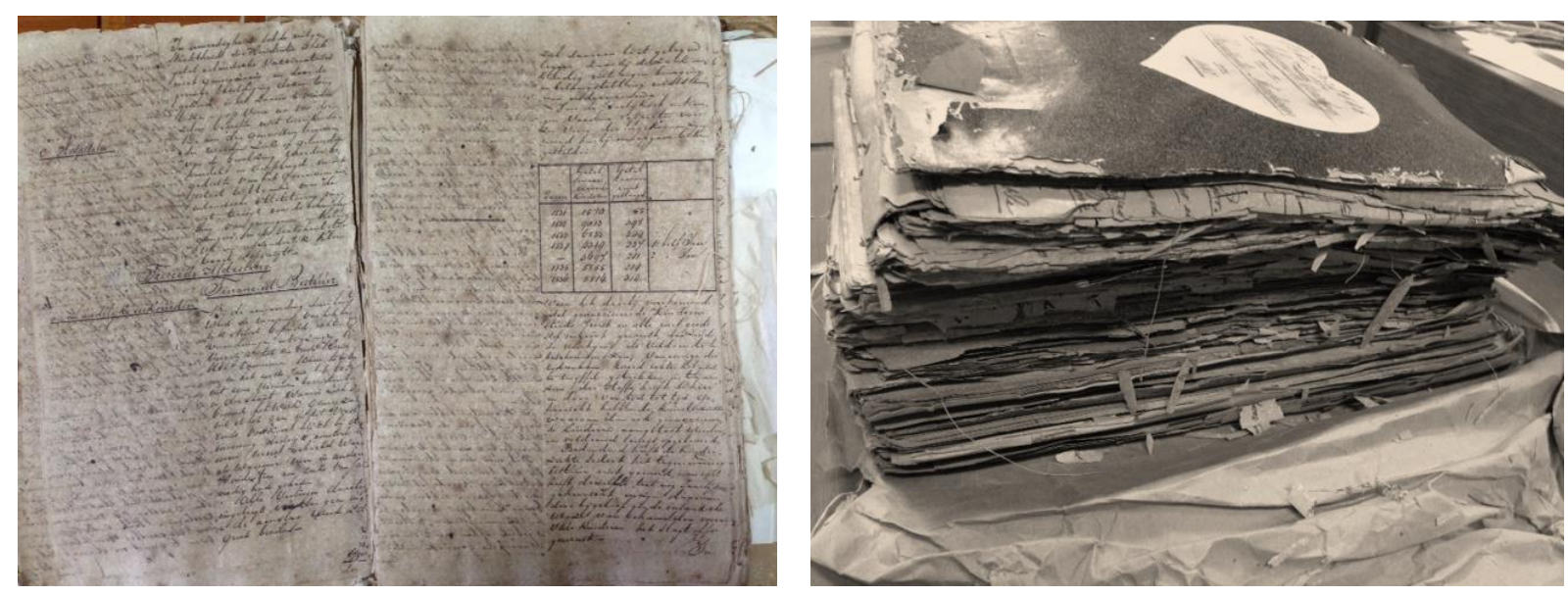

Sejarawan pada era post-nasionalis saat ini telah menjadi semakin sadar bahwa profesi mereka bertumbuh pada tumpuan negara-bangsa modern, kata Reid. Mereka berupaya menyusun secara kronologis urusan-urusan utama sebuah negara-bangsa. Pola itu telah berubah dalam arus historiografi yang terus bergerak, yang dalam konteks Indonesia bergeser dari apa yang disebut model neerlando-sentris ke Indonesia-sentris. Pergerakan historiografi juga telah memotret respons dan posisi masyarakat atas kemunculan dan perkembangan negara-bangsa, dan dengan demikian mendobrak dominasi kerangka kajian sejarah yang berpaku pada tokoh dan pusat kekuasaan. "Upaya kita [sejarawan] dalam mengepaskan keberhasilan spektakuler (dan kegagalan) dari negara-bangsa di masa modern telah membuat kita membandingkannya dengan institusi-institusi sosial dan politik yang diwariskan nenek-moyang kita dari masa pra-negara-bangsa. Melalui perbandingan itu, kita berimajinasi tentang suatu masa ketika tidak ada satu institusi tunggal yang sangat mendominasi aneka struktur masyarakat. Upaya-upaya ini telah memberikan kesegaran pada model klasik kajian sejarah. Meskipun demikian, pada era global sekarang ini, menurut Reid, sejarawan tak akan dapat bertahan hanya dengan berfokus pada kajian sejarah yang berparadigma nasionalis dan mengabaikan keterhubungan global di masa lalu dan sekarang (Reid, 2015: xviii).

Secara umum, sejarawan bergulat dengan sumber-sumber primer yang merentang puluhan bahkan ratusan tahun usianya. Sebagai hakikat dari metodologi dalam ilmu sejarah, pergulatan dengan sumber-sumber primer membungkus kerja 
sejarawan dalam lingkup kajian yang spesifik dan terpaku oleh periode tertentu. Namun, hakikat metodologi bukanlah pembacaan atas sumber-sumber primer yang "berbicara pada dirinya sendiri". Hakikat metodologi sejarah adalah bahwa keunikan sumber primer-akibat lintasan usianya - menjadi kekayaan bagi kerja sejarawan agar terlibat (engaged) dengan konteks mutakhir peristiwa jaman.

Kemajuan teknologi komunikasi digital menghadirkan tantangan besar bagi peng-aktual-an kerja sejarawan. Peng-aktual-an itu setidaknya ditandai oleh dua ciri. Pertama, sejarah sebagai ilmu dituntut semakin bersifat kosmopolitan dalam hal pendekatan, metode dan diseminasi narasi. Kedua, dalam konteks semakin kosmopolitannya ilmu sejarah, sejarawan dihadapkan pada keharusan mengembangkan perspektif kajian yang engaged dan merespons isu-isu aktual dan kontemporer meskipun objek kajiannya merentang waktu hingga puluhan bahkan ratusan tahun lalu. Dua tantangan tersebut mendesak direspons sejarawan di masa sekarang agar tidak teralienasi dari dinamika cepat dunia kontemporer.

\section{KESIMPULAN}

Teknologi komunikasi digital telah memberi alternatif terhadap makna dimensii ruang fisik dan ruang temporal dari suatu peristiwa. Akibat kecepatan transformasi peristiwa dan persebarannya, batasan "periode" tidak lagi terpaku pada satu rentang kronos berdimensi ruang yang besar. Dalam hitungan detik sebuah fakta dari suatu peristiwa virtual telah dapat berubah makna sehingga prinsip periode sebagai "pembentuk" atau "pemberi " makna pada suatu peristiwa, dapat sangat tipis ruangnya. Penyempitan ruang kronos dalam konsep periode adalah fakta dalam sejarah dunia yang sedang menjadi saat ini.

Teknologi komunikasi digital juga telah menciptakan apa yang disebut realitas virtual dari suatu masyarakat virtual. Kendati menghadirkan masyarakat dan realtias virtual, secara global dan khususnya dalam konteks Indonesia teknologi komunikasi digital memiliki makna ekonomi langsung yang secara konkrit besar nilainya. Fakta ini menegaskan bahwa dunia virtual telah menjadi bagian sekaligus menjadi alternatif terhadap wujud dan mekanisme lain struktur konvensional ekonomi yang berlaku selama ini. Sebagai bagian dari struktur yang berlaku saat ini, makna dan nilai ekonomi dari realitas virtual dan masyarakat virtual adalah profil dunia kontemporer yang tak mungkin dielakkan.

Kajian sejarah dan para sejarawan menghadapi tantangan serius terkait dengan cara kerja di tengah dunia kontemporer yang geraknya bertumpu pada keterhubungan global. Sejarawan dituntut menyesuaikan pendekatan dalam kerjanya dengan pola, bentuk dan karakteristik dunia kontemporer yang sangat dinamis, bergerak menuju kosmopolitanisme global dan nyaris tanpa batas. Penyesuaian tersebut dapat menyentuh baik metodologi maupun bentuk diseminasi narasi. Meskipun objek material kajian sejarah adalah peristiwa masa lalu yang secara hakiki terikat oleh kerangka ruang-waktu, keterhubungan global pada dunia kontemporer menuntut adanya peng-aktual-an makna peristiwa melalui pendekatan yang lebih fleksibel dan adaptif terhadap platform kekinian yang serba digital. 


\section{DAFTAR PUSTAKA}

Castells, Manuel. 2000. The rise of the network society: The information age: Economy, society and culture, Volume I: The rise of the network society (Hoboken, NJ: WilleyBlackwell)

Giddens, Anthony. 2009. The politics of climate change (Cambridge: Polity Press)

Huntington, Samuel. 1996. The clash of civilizations and the remaking of world order (New York: Simon \& Schuster).

Reid, Anthony. 2016. 'Humanities in Indonesia for a Global Age', Humaniora 28 (1): 111

Reid, Anthony, 2015. A history of Southeast Asia: Critical crossroads, (Sussex: Blackwell) Rifkin, Jeremy. 1995. The end of work. The decline of the global labor force and the dawn of the post-market era (New York: Putnam Publishing Group)

Toffler, Alvin. 1980. The third wave (New York: William Morrow \& Company).

\section{Website:}

https://www.goodnewsfromindonesia.id/2016/01/21/data-terbaru-ternyata-jumlahponsel-di-indonesia-melebihi-jumlah-populasi

http://www.tempo.co/read/kolom/2015/10/02/2310/indonesia-raksasa-teknologidigital-asia;

https://www.kominfo.go.id/content/detail/6095/indonesia-raksasa-teknologi-digitalasia/0/sorotan media

http://nasional.kompas.com/read/2012/06/08/03204285/wajah.baru.kelas.menengah.in donesia

http://nasional.kompas.com/read/2012/06/08/13003111/Siapa.Kelas.Menengah.Indone $\underline{\text { sia }}$

https://hiveminer.com/Tags/england,telefonzelle

Https://Www.Bukalapak.Com/P/Handphone/Hp-Smartphone/5oe93t-JualSamsung-Galaxy-J3-Pro-2017-Free-Ongkir-Dual-Sim-16gb-Ram-2gb-BnibNew-Original?Blca=Sesho-Awalp\&Gclid=EaiaiqobchmiqpgigV91givvafoch0bvw9keaqyasabegjaupd Bwe

Https://En.Wikipedia.Org/Wiki/Alexander Graham Bell

Freiburg, 3.12.2017/AS 